\title{
Crossing the boundaries: Collaborations between mathematics and science departments in English secondary (high) schools
}

\author{
Victoria Wong ${ }^{\mathrm{a} *}$ and Justin Dillon ${ }^{\mathrm{b}}$
}

${ }^{a}$ Department of Education, University of Oxford, Oxford, UK; ${ }^{b}$ Graduate School of Education, University of Exeter, Exeter, UK

vicky.wong@education.ox.ac.uk Orcid: 0000-0002-1735-0045

J.S.Dillon@exeter.ac.uk Orcid: 0000-0001-5154-8306

Victoria Wong was supported by the Rosalind Driver Research Scholarship Fund at King's College London. She teaches pre-service science teachers at the University of Oxford.

Justin Dillon is Professor of science and environmental education in the Graduate School of Education at the University of Exeter.

\section{Acknowledgements}

This research was funded by the Rosalind Driver Research Scholarship Fund at King's College London. Thanks to Heather King at King's College London.

Word count: 9113 words 


\title{
Crossing the boundaries: Collaborations between mathematics and science departments in English secondary (high) schools
}

\begin{abstract}
Background

There are frequent calls in the literature for school science and mathematics departments to collaborate, largely in response to perceived overlaps and similarities between the two subjects in the context of Science, Technology, Engineering and Mathematics (STEM). Yet few studies explore how such collaborations might work. This paper is unusual both in its focus on mathematics/science collaborations which have not arisen from a specific shortterm intervention and in its focus on the views of practising teachers rather than policy-makers or curriculum developers.
\end{abstract}

Purpose

We ask how and why collaborations get started and explore how mathematics and science departments actually work together in secondary (high) schools in England. We ask what some of the affordances and challenges are in both initiating and sustaining collaborative practice.

Design and methods

After a prolonged search for collaborations, six schools were identified and visited and semi-structured interviews carried out with the 15 teachers most closely involved in collaborating, to explore their perspectives and insights.

Results

The findings show that collaborations are possible, though they are challenging to sustain, and they can be approached in a number of ways. Mathematics/science collaboration can be a key site of professional learning for teachers, particularly about the 'other' curriculum. Informal conversations across departments were 
highly valued but tended to be between those with a well-established pre-existing relationship. While physical structures can support collaboration, it needs strong support from senior leadership teams to begin and can cease if that support stops.

Conclusion

Contrary to the commonly espoused view that there are many overlaps and similarities between mathematics and science in school, it can be a significant challenge for teachers to find them. Collaboration is not-neither straightforward either to begin or-nor to sustain. Authers-Researchers and policy-makers should thus be cautious about recommending collaboration as straightforward for science and mathematics teachers to adopt. These conclusions provide a major challenge to simplistic advocacy of STEM in schools.

Keywords: science, mathematics, collaboration, STEM

\section{Introduction}

\section{Calls to work together}

There have been many calls in the literature, and more widely, for school science and mathematics departments to work more closely together. Arguments for such closer alignment are often based on perceived synergies in subject content such that as there is substantial overlap between the subjects which consequently makes collaboration useful and teaching more efficient and effective (see: Dodd \& Bone, 1995; Orton \& Roper, 2000; Pang and Good, 2000; Osborne, 2011; Zhang, Orrill, \& Campbell, 2015; Boohan, 2016). For instance, Zhang et al. argue that 'mathematics and science share a coherent set of values and concepts' (2015, p. 358) including problem solving and process skills. They suggest that: 'The content of both science and mathematics should encourage teachers to integrate and use new knowledge and skills from across areas of 
competence' (ibid.). Zhang et al. also suggest that it should be relatively easy to find overlap in the content of the two curricula.

The other main arguments for closer working include: shared values and skills (Berlin \& White, 1995); a resulting improvement in students' scientific and mathematical understanding (Pang \& Good, 2000); an opportunity for teachers to appreciate similarities and differences in the curriculum (Boohan, 2016); subsequentthat it promotes transfer of learning between the disciplines (Honey, Pearson, \& Schweingruber, 2014); and, that it enhanceds pupil engagement particularly when 'real world' contexts are used (Williams et al., 2016, Venville, Wallace, Rennie, \& Malone, 2002, Honey et al., 2014).

This study was carried out in England where there has been a recenthave been moves to increase in the mathematics content of the science curriculum, leading to further calls for mathematics/science collaboration (for example by Boohan, 2016).

\section{Limited existing research}

In spite of these many calls for collaboration, Osborne rightly identifies a lack of empirical research exploring how science and mathematics educators can actually work together more closely:

Science and mathematics education exist at a distance from each other - the two communities rarely engage and there is an absence of a literature that explores how they could work symbiotically. (2011, p. 98)

Those who have surveyed the literature on mathematics/science collaboration (including Orton \& Roper, 2000; Pang \& Good, 2000; Becker \& Park, 2011; Czerniak \& Johnson, 2014; Honey et al., 2014) agree that there are very few empirical studies. Those which do exist have often researched the outcomes or impacts of a specific short-term 
intervention. For example, Frykholm and Glassom (2005) and Koirala and Bowman (2003) studied their integrated pre-service teacher education programmes; and Weinberg and Meeking (2017) followed up an intervention with serving science and mathematics teachers. Venville et al. (2002) found a variety of integrated practice in school settings though t. They resisted placing the different versions of integration along a curriculum continuum, not wishing to imply 'that more integration was synonymous with better integration' (p. 76). We have followed their lead, and have likewise not drawn up a continumm of the collaborative practice found in schools.

This study is, in comparison with previous studies, unusual in its focus on a range of collaborations in schools rather than those resulting from any particular intervention. It asks:

- Why do-science and mathematies teachers begin to collaborateis collaboration initiated and by whom?

- What do mathematics/science collaborations look like in practice?

- What are the affordances and constraints in developing and sustaining collaborative practice?

Very few of the existing studies have focused on serving teachers' views and practices of collaboration or explored why teachers might choose to begin to work across departmental boundaries. This study seeks to offer important insights which addresses that gap-albeit to a relatively limited extent.

\section{Terminology}

Searching the literature for previous research about mathematics/science collaboration is made challenging due to a wide variation in language and terminology. Many authors call any working together 'integration' but a number of authors, for example, Czerniak 
et al._(1999), Berlin and Lee (2005) and Williams et al. (2016) argue that the term 'integration' is problematic, largely because there is a lack of an agreed definition. We have chosen the term 'collaboration', and use it to mean any form of working together by teachers from mathematics and science disciplinary backgrounds and departments which focuses on teaching and learning.

\section{Collaboration}

Many authors have written about collaboration (see, for example, Perkins, 2003; Carlile, 2004; Edwards, 2011) but, whatever the context, they virtually all agree that collaboration across boundaries, including disciplinary boundaries, is not straightforward. In their review paper, Wilson, Schweingruber and Nielsen (2015) focused on how to support US science teachers' learning across their careers. They argue that collaboration can be a key site of teachers' professional learning and development. However, they note that evidence of a resulting 'learning environment for teachers of science is both limited and diffuse' (p.148) and that where there is a focus on collaborative practices, it is a departure from the more individualistic cultures which characterise most school workplaces. Wilson et al. (ibid.) further note that relatively few studies have explored how teacher interaction supports teacher learning, particularly in science education, and ffFurthermore, that they argue, workplaces are often poorly organised to support collaboration and, thus, building and sustaining it can be a key challenge, with access to external support frequently a significant factor in successful examples.

UK science departments usually have a team room which is generally only used by members of that department. This room can be a caring and supportive place and is $a$ 
key site of collaborative learning (Burn, Childs, \& McNicholl, 2007), but in spending

the majority of their time within the department teachers are less likely to get to know members of other departments, including the mathematics department.Childs, Burn and McNicholl (2013) identified the importance of departmental leadership in fostering collaborative practice and how leaders can promote a culture of collaboration by modelling it in their own behaviour.- They argue that this issue is particularly important for science departments as science teachers regularly have to teach out of specialism and that, combined with constant curriculum change, frequently casts them as learners. The only people they can realistically learn from are each other.

Mawhinney (2010) found that shared spaces such as teachers' lounges and $\underline{\text { staffrooms were important for collaboration and frequently acted as sites of professional }}$ knowledge sharing and communication. UK science departments usually have a teamroom which is generally only used by members of that department. This room can be a caring and supportive place and is a key site of collaborative learning (Burn, Childs, \& McNicholl, 2007), but in spending the majority of their time within the department, teachers are less likely to get to know members of other departments, including the mathematics department. Consequently,

cGellaborative practice is more likely to be found within subject departments than across departments.

For example, UK science depatments usully hava team rom which is

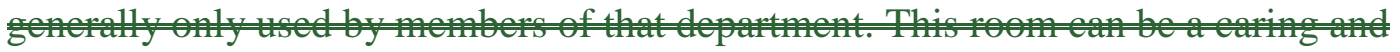

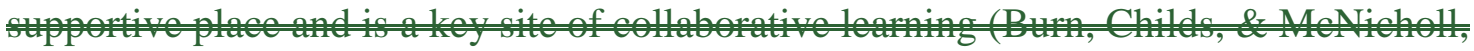
2007 ), but in spending the majority of their time within the depatmenteachers are less likely to get toknow members of other departments, including the mathematies department. 
$\underline{\text { Ball (1987) argues that secondary school teachers have undergone a lengthy }}$ process of socialisation into their particular subject-such that they become separated from other areas of specialism. Grossman and\& Stodolsky (1995) suggest that shared beliefs and norms thichthat develop among teachers of a particular subject can be characterised as a subject subculture, such that issues and policies that they view as problematic can vary. They suggest that in creating interdisciplinary structures to replace subject departments it is necessary to acknowledge the subject-specific background and concerns of the teachers involved.

Hargreaves and Macmillan (1995) agree that departments are subgroups of the school community. They suggest that they are balkanised, by which they mean they are: strongly insulated from each other; the groupings are relatively permanent over time and space; teachers identify with these sub-groups; and they are repositories of their self-interest and status. It is thus extremely challenging for teachers to break out of them.

In terms of research into the nature of collaborations, Nelson and Slavit (2007), in a study of mathematics-science teacher professional learning community groups, found that participants appreciated the opportunity to familiarise themselves with the 'other' curriculum. Nevertheless, the teachers found it challenging to find common ground across mathematics and science for an inquiry project, with many struggling 'to define an inquiry question that would cut across the disciplines' (p. 29). As a result, they tended to focus on 'pedagogy or classroom processes as opposed to specific disciplinary ideas and student understanding' (ibid.). 


\section{Theoretical frantework: $b \underline{B}$ oundaries and exchange value}

\section{Bernstein and boundaries}

In spite of arguments about commonality between the disciplines, there are existential boundaries around mathematics and science departments in schools (Hargreaves \& Macmillan, 1995; Wong, 2018; Wong and Dillon, 2019), and in order to work together mathematics and science teachers must cross them. Bernstein's ideas of classification (2000) help to explain why boundary crossing is a major challenge.

Bernstein $\underline{\mathrm{He}}$ argues that in order for categories (in this case school subjects) to be different from each other, they need a space in which to develop their unique identity. This space exists in the distance which separates one subject from another. As-Bernstein puts itargues that, in order to be differently specialised 'they must have a space in which to develop their unique identity [...] and special voice' (p. 6). He also argues that the crucial space which allows the specialisation:

\footnotetext{
is not internal to that discourse but it is the space between that discourse and another. In other words, A can only be A if it can effectively insulate itself from B. In this sense, there is no $\mathrm{A}$ if there is no relationship between $\mathrm{A}$ and something else. The meaning of $\mathrm{A}$ is only understandable in relation to other categories in the set $[\ldots]$ Whatever maintains the strengths of the insulation, maintains the relations between the categories and their distinct voices. (Bernstein, 2000, p. 6)
}

In other words, the identity of one subject is reliant on it being different from, separated from, or insulated from another subject. Thus science can only be science if it can effectively insulate itself from mathematics; mathematics can only be mathematics if it can effectively insulate itself from science. If the insulation between the categories is broken then it can become impossible to identify where one ends and the other begins and their unique identity is eroded. 
In cases where classification is strong, the boundaries between subjects are strong and the subject is well insulated. The insulation between mathematics and science in school is produced by differences in discourse and language, by specialised teachers, by specialised teaching spaces and support staff (technicians). In English secondary schools, the boundaries between the sciences - biology, chemistry and physics - are relatively strong (Jenkins, 2007); the boundary between science and mathematics even more so as discussed above.

\section{$\underline{\text { Leadership and change }}$}

School departments are usually led by a head of department (often referred to as a Chair in North America) and Bernstein (2000) suggests that in a strongly classified system, it is the heads of departmentthey who will communicate rather than other members of the team. Ball (1987) noted that relationships between departments are frequently characterised by conflict:

Conflicts over access to scarce resources - time, personnel, capitation, territory and pupils, or at least particular varieties of pupils - are enjoined between departments. (Ball, 1987, p. 42)

Ball argues that 'where relationships between teachers are poor almost any attempt at innovation can be seen [by colleagues] in terms of the political motivations or career aspirations of the instigators' (1987, p. 227). Thus, unless the relationship between the departments is good in the first place, science or mathematics teachers advocating collaboration might very well be viewed with suspicion.

Educational change can arise in a variety of ways but Ball (1987) identifies the headteacher (principal) as critical. It is the head who usually introduces change into the school and even when this is not the case their support is necessary for any innovation proposed by another member of staff (Ball, 1987). The head can also be critical in 
resisting change. The key role that the headteacher and senior leadership team play was also identified by Straw, MacLeod and Hart (2012) who found that change in practices within and between departments proved difficult in schools where that innovation did not feature among senior leaders' priorities or, at least, have their support.

\section{Grossman and Stodolsky (1995) argue that department chairs (or-heads of}

department) act as brokers of reform and can promote or resist efforts to bring about change. Childs et al. (2013) argue that heads of department are the ones who can promote or block collaborative practice.

_Were a teacher to wish to work collaboratively across science and mathematics, therefore, they would need to have their head of department onside, as well as the headteacher and the head of the other department. In a busy school, getting this much agreement between parties could prove a significant barrier.

\section{Obstacles and exchange value}

In a review of interdisciplinary mathematics education, albeit not focused specifically on links with science, Williams et al. note that:

\footnotetext{
Interdisciplinary work can be difficult, confronting certain sorts of obstacles, power structures, and questions of identity, differences in understandings of knowledge, discourse and practice. (2016, p. 6)
}

Given all these obstacles and barriers, the surprise is not that collaboration is rarely found, but that it is found at all. Williams et al. argue that as a person becomes more associated with a discipline and identifies with it, they can become blind to other disciplines, or see other disciplines in a distorted way, creating further challenges to working in an interdisciplinary manner. They identify particular problems with interdisciplinary projects. In the normal organisation of society, products are exchanged by means of what they call a 'generalised exchange form' (p. 10); in most instances this 
process takes the form of money. Participants in the exchange know what they are giving and what they are receiving. Williams et al. argue that when two or more disciplines work together they may have no medium of exchange. They argue that it is hard to define a common objective which often leads to the failure of interdisciplinary projects. $\mathrm{In}$, while- in successful projects the outcomes makes sense within each discipline. Thus considering the outcomes of a joint enterprise, and how those outcomes contribute to broader educational outcomes in each of the disciplines, is arguably a key to successful interdisciplinary work.

This study is in the context of a forthcoming change to curricula in England, where there is to be anwhich, as said before, will involve an increase in the amount of mathematics in science. There have which has led to been consequently calls for an increased in the amount of collaboration between mathematics and science departments (for example by Boohan, 2016), yet we know that such collaboration is rare in England. What drives this study is that, in our professional experience, examples of science and mathematics collaborations can be found. The existence of these tantalisingly rare examples of success provides opportunities to investigate questions such as: Why do science and mathematics teachers begin to collaborate? And what What do mathematics-science collaborations look like in practice? And what are some of the barriers and affordances to collaborative practice? The answers to these questions might go some way to explaining the scarcity of successful, long-term collaborations.

\section{The study}

$\underline{\text { In order to explore collaboration we needed first to identify schools with collaborative }}$ practice with the aim of interviewing those most closely involved to get their perspectives on the collaborations. The study necessarily required purposive sampling 
with schools invited to participate that possessed the required characteristics (Cohen, Manion, \& Morrison, 2011).

-Our starting point for identifying schools was our own personal knowledge of schools where mathematics/science collaborations had or were taking place. Our knowledge was supplemented by suggestions from colleagues and by searching educational websites including those of individual schools. After a substantial search effort we identified a number of potential schools that might provide evidence to address the research questions. Even with contacts in severat-dozens of schools as a result of the authors working across a number of university teacher education programmes, it was difficult to find schøels-institutions where the departments were collaborating. The first author attended STEM (Science, Technology, Engineering and Mathematics) teacher professional development and presentations about mathematics at a science education conference with the specific aim of identifying suitable schools and, as a result, was invited into three of the-schools. Existing contacts of the authors were used to identify and gain access to the other three.

$\underline{\text { Site } V \forall i s i t s ~ w e r e ~ p a i d ~ t o ~ s i x ~ E n g l i s h ~ s e c o n d a r y ~ s c h o o l s ~(f i v e ~ s t a t e, ~ o n e ~ f e e-~}$ paying) (see Table 1) known for some aspect of mathematics/science collaboration in 2014-2015. At each school, semi-structured interviews, based on the research questions, were carried out with those teachers most closely involved in the collaboration; in total there were 15 interviews each about an hour long. In addition, observation data about the organisation of the departments and the location of the teaching spaces were collected and, where appropriate, documentary data including policies and curriculum booklets related to the collaborations. This process allowed us to explore how the collaborations began, what they looked like and what the teachers believed were the barriers and affordances to collaboration. 
The research approach evolved as it progressed. Whilst the original intention was to interview the head of science, head of mathematics and a member of the senior leadership team, it became apparent that these were often not the people most closely involved in the collaboration and in only one school were people who held these three posts interviewed. In two schools a key person involved in the collaboration had subsequently left and in these schools there was only one research participant. While we would have preferred multiple perspectives to each collaboration, these two schools provided important insights, particularly into how and why collaboration can reduce or even cease and thus are included even though they did not quite fit the original research design. Unlike in some other countries, senior leaders in schools in England almost always teach classes, (as did all those interviewed) alongside their leadership responsibilities. See Ttable 1 for a full list of all participants.

\section{Ethics}

BERA ethical guidelines (BERA, 2011) were followed and the planned study approved by King's College London research ethics committee. A particular ethical consideration is that of conversations which could have the potential to cause dissent within the school. There are different degrees of anonymity (Wengraf, 2001) and we anticipated that participating teachers will be able to recognise themselves and therefore their colleagues in what is written and thus we have taken great care in how we have reported, for example, descriptions of friction or frustration between colleagues and school departments. Such relationships can be fragile, as this study shows, and we would not wish participation to lead to further tension. 


\section{Interviews}

All of the interviews were carried out by the first author - an interview schedule is available in Appendix 1. Questions focused on the nature of the collaboration, how and why it began and the challenges teachers faced in building and maintaining it. The researcher's background as a teacher helped in developing trust giving her greater access into teachers' worlds and giving her the 'empathy to elicit personal stories [and] in-depth description' (Rubin and Rubin ${ }_{2}+1995$, p.13).

\section{Permission was sought and granted to audio--record the interviews. All} interviews took place withinat the schools at a location of participants' choosing, usually an office or meeting room. All were around 45-60 minutes in length.

-The interviews were transcribed and data analysed using NVIVO to manage the data. Data were coded using a complete coding process as recommended by Braun and Clarke (2013), with inductive coding based on the data set (Charmaz, 2006) (for example, Very few teachers have the skills to teach maths and science or Projects difficult for lower achievers) together with deductive coding based on the theoreticat frameworktheory (for example: Physical proximity and spaces or Key person). Most codes were evident in more than one interview and some were present in most interviews (Braun \& Clarke, 2013). All coding was carried out by the first author in discussion with the second author and other colleagues. Themes were developed from the codes as described by Braun and Clarke (2013), with concepts, topics or issues which several codes were related to being searched for. Findings from the interviews were checked against each other and discussed by the authors. The documents from schools were analysed for their content and examples of how the collaboration functioned in practice. Not all schools consented to provide documentation.

All names including school names are pseudonyms. The schools' interviewee codes are as follows: the first letter corresponds to the school (A-F), the second to the 
subject ( $\mathrm{S}$ - science, $\mathrm{M}$ - mathematics, $\mathrm{T}$ - technology) and there is an $\mathrm{L}$ added for a senior leader.

\section{Results: The schools}

In this section we describe the schools, the participants and the nature of the collaboration. Details of the schools, the departments and the participants are shown in Table 1.-

Note that an AST is an Advanced Skills Teacher - these are teachers who were employed in roles which included an element of work dedicated to supporting teaching colleagues in their own schools, and other schools in the area, to improve their own practice. The role was introduced in 1998 to reward excellent teachers who chose to stay working in classrooms, rather than following other routes to promotion through leadership. Such roles are now rare).-

An academy is a state school with a new form of governance outside local authority control.

An academy chain is a partnership between a group of academies, often led by one particular academy. The schools can be near or far from each other.

[Insert Table 1: The Schools, departments and participants_about here]:

\section{RQ1: How and why is collaboration initiated and by whom?}

We found that leadership wasappeared to be critical in the initiation of collaboration. Previous studies (such as Grossman \& Stodolsky, 1995, and Childs et al., 2013) found that leadership within the department was important in promoting collaborative practice. Our findings, however, suggest that cross-department collaboration requires support, or even promotion, by leadership from higher up the school or even outside it.

Bernstein (2000) suggests that when classifieation weakens, as happens when mathematies and science departments collaborate, that when departments begin to 
collaborate one should ask which group is responsible for initiating the change and whether they are dominating or dominated - in other words whether they come from the top or the bottom of the institution. Asking this question allowed us to demonstrate the importance of leadership by dominant groups in overcoming department barriers. We further found that each Within this study, each-collaboration eame-was initiated as the response to a different stimulus, but all those stimuli were external to the departments and some external to the school.

At Ayford ${ }_{2}$ AM, as part of Cambridge University’s Millennium Mathematics project, was asked to find a teacher of another STEM subject within the school and develop a way of working together. In Beebury ${ }_{2}$ the academy chain encouraged integrated teaching and a new building was designed to facilitate it. At Ceeton ${ }_{2}$ a new building was designed to support collaboration and it was encouraged by senior leaders. At Deecom ${ }_{2}$ there was external funding, specifically for cross-department collaboration, channelled through a deputy headteacher. In Eyston, the departments were moved together by the headteacher to encourage conversations. At Effdon ${ }_{2}$ a 'mathematics across the curriculum workshop' attended by CML led to a questionnaire and wholeschool response.

While most schools in England have a traditional department structure including heads of science and mathematics, it is conspicuous that three of the six collaborating schools had both a non-traditional structure and physical arrangements of departments designed to promote collaboration. In a study of collaborating schools in the early 1980s, Hart, Turner and Booth (1982) similarly found that collaboration was more likely when science and mathematics were grouped in the samea faculty. 
The decisions both to organise the school in a non-traditional way - in larger faculties rather than departments - and then which subjects to group together, were taken at a senior level in the schools, again demonstrating the importance of senior leadership in the initiation of collaboration. In Beebury ${ }_{2}$ the decision firstly to organise as faculties and promote collaboration came from the academy chain and sponsors, in other words by leadership which is not only senior to heads of department but also senior to the head of the school. It is also noticeable that in none of the six schools was the collaboration initiated by discussions between the heads of science and mathematics.

Impetus for collaboration came from a dominating rather than a dominated group and from the top of the institution. Thus the collaborations, at least in five cases were less a free choice by individual science and mathematics teachers than a result of compulsion by those in authority.

Ayford, however, is a notable exception as the collaboration was initiated by AM who, as an Advanced Skills Teacher, was working outside the traditional department and school hierarchy. AM was highly respected and valued by ATL and the school leadership and consequently tended to be allowed significant freedom to experiment with different ways of working, which included cross-department collaboration.

\section{RQ2: What does collaboration look like?}

In this section we will explore what the mathematics/science collaborations looked like in practice, together with the affordances and constraints to collaboration, using primarily the interview data and drawing on the documentation.- Four different types of collaboration or ways of working together (Table 2) were identified in the data; each is discussed in turn. Following Venville et al. (2002) we have resisted placing the types of 
collaboration on a continuum or any typology of integrative or collaborative practice which assumes more collaboration is necessarily preferable. Our key finding is that whatever the collaboration type, a significant challenge was finding points of overlap between the mathematics and science curricula.

[Insert Table 2: Types of collaboration in the schools_about here]

\section{a) Joint projects and lessons}

Projects which were run across mathematics and science - and in some cases technology - were what many people described when asked about mathematics/science collaboration. All except one example were for aimed at pupils aged 11-13 years.

\section{Ayford}

Ayford had a week-long joint project for Year 9 based around whether a bath would cool more slowly with bubbles. They were not very pleased with this as a context, but had struggled to find one more suitable; similar towhich resonates with the-difficulties difficulty teachers had identifying highlighted byinquiry questions which cut across both disciplines in Nelson and Slavit’s (2007) study. Work was divided between what had to be covered in science and in mathematics in successive lessons. AM and AS wanted to produce data which could be used with both a mathematics and science focus. AM was keen to ensure students understood both the similarities but also the differences in how mathematies and science would use the information.that teachers in the project were:

Highlighting the similarities and highlighting the differences between the approaches [in mathematics and science] AM

The emphasis on differences between the subjects was unique to Ayford. AM and AS described several problems that made life very difficult for the teachers including that 
they would not know what students had achieved in the previous lesson, which could vary widely. These difficulties and the unease with the context led to the project's demise.

AM and AS also organised the only joint reported collaborative activity for students older than 13 years, an extra-curricular activity for 15-17-year-oldss to encourage students to study particularly physics and mathematics beyond the age of 16 . They used the-a press release from CERN when they thought they had data to show particles were travelling faster than light (CERN, 2011). Students were shown a documentary about the dilemma followed by some input on the Lorentz transformation and similar-problems for students to tackle in groups. It was a very popular session, although a huge amount of work to set uM reported that: 'The students loved it. It was really, really exciting', however it 'was a huge amount of work to set up'. Nevertheless, they are keen to do something similar with that age group again.

\section{Beebury}

\section{At Beebury, initially all The projects at Beebury were originally for all of the} mathematics, science and technology teaching in Years 7 and 8 (students aged 11-13 years) was through the medium of projects. The projects were jointly planned by a teacher from each of mathematics, science and technology and initially focused on competencies. The teachers $\underline{\mathrm{BS}}$ acknowledged that initially subject content was lostwith healthy eating studied several times which was demotivating for students and frustrating for the teachers:

To begin with, the curriculum was disorganised [and] focussed on developing competencies as its primary objective and then second to that was subject knowledge, but when the kids had studied a balanced diet five times, I felt that maybe we were missing the point. [BS]

- This example again shows the difficulties that teachers find with identifying content which cuts across the disciplines, as Nelson and Slavit (2007) found. All the Beebury 
participants agreed that teaching integrated MST is difficult for many reasons, including that it challenges secondary teachers' identities as subject specialist teachers as well as requiring them to teach material that they may well not be familiar with - both factors identified by Venville et al. (2002) as barriers to collaboration. The principal had decided that the following year students were going to spend more time in separate subjects, rather than following integrated projects, due to concerns about student progress::

The fundamentals weren't being developed as much as they should be because we needed more subject specialist input in there. [BSL]

This example again demonstrates that leadership beyond head of department level is critical in maintaining collaboration.

\section{Ceeton}

At Ceeton, the joint project was between mathematics, science, technology and physical education, and lasted six 6 weeks at the start of Year 7 (ages 11-12 years). The project context was-about making smoothies (a blended fruit drink), although CML hoped to find a more rigorous context for a future project,:

Making smoothies, which is not really want we want, [but] it was a place to start [...] it's very hard to get the level of maths necessarily you want to or the level of science you necessarily want to out of a collaborative project. [CML]

CML hoped to find a more rigorous context for a future project - once again showing the difficulties in finding suitable points of overlap in the curriculum. The project work and included statistics in mathematics and digestion and energy in science. The original idea was that teachers from different disciplines would team-teach, but in the end it was 
decided that it would be easier to deliver if the content was split between the different subjects. With the subjects separated they avoided some of the challenges at Ayford and it was expected to continue. As the mathematics teachers, in particular, were concerned about student progress during the time of the project they atso-had some separate science and mathematics lessons during this time which were not dedicated to thealongside the project as the mathematics teachers, in particular, were concerned about student progress. This finding resonates with Grossman and Stodolsky (1995) who found that mathematics teachers were more likely to view the subject as inherently sequential, and thus be concerned with changes which interfered with that sequence.

\section{Deecom}

Deecom had had two separate projects. One-The first, for Year 7, involved students doing some practical work related to Hooke's Law in science before taking the results to use in mathematics. It was described by DS as a mathematics project that science assisted. The second, for Year 8, project was in the context of the topic 'Space' and involved several lessons across both mathematics and science. The project began with the science context to which the mathematics was added; identified by Pang and Good (2000) and Frykholm and Glassom (2005) as a common approach in joint projects. Students had a booklet and were expected to work largely independently to research and complete the work which could be done in either mathematics or science.

Unfortunately, not all students responded well to the increase in responsibility they were given for managing their own learning, which caused difficulties with classroom management:

It was difficult for some staff to manage that level of, not necessarily off task, but independent work [...] there were behaviour issues I think for some people to start with. [DS] 
$\doteqdot$ Behaviour management was previously recognised by Czerniak and Johnson

(2014) as a barrier to integrated teaching. The integrated project thus did not necessarily enhance pupils' engagement with science and mathematics, although this was suggested as a key goal for integration by Venville et al. (2002) and others.

\section{b) Visiting Expert}

The 'Visiting Expert' model for collaboration had been developed by AM and AS at Ayford. They spoke about it at a national education conference and, as a result, Ceeton tried the idea, with some apparently small but significant alterations. It involves a subject expert visiting a lesson of another subject to give a short specialist input.

\section{Ayford}

For AM and AS, 'Visiting Expert' was a quick and simple way to collaborate. It involved one teacher going into the other's lesson to do a 5-10 minute introduction to an aspect of mathematics which would be useful in science or vice-versa. They gave two examples of its use: AS had talked about mirrors and reflection and set up a problem for AM's lesson about symmetry. AM had talked about calculating the volume of complex shapes by approximating to a straightforward shape as an introduction to AS's lesson on lung capacity. Although they had not used 'Visiting Expert' extensively, both felt that even occasional use was beneficial, and in each case there had been some prior planning. Indeed, finding examples could be challenging and both recalled that when AM originally asked for contexts for teaching symmetry AS struggled to think of any;:

Symmetry to [AS] didn't mean reflections and he didn't immediately make the link with mirrors and we found that actually there's rather a lot that I would call symmetry, but that he hadn't thought of in that way. [AM]

-They eventually deciding decided on angles of incidence and reflection-, which-These are not often described as 'symmetry' in school science, although clearly they are an 
example of it. These difficulties are an example of the difference in discourse identified by Williams et al. (2016) as a barrier to collaboration.

\section{Ceeton}

At Ceeton, the close proximity of departments and the glass walls of the classrooms allowed staff to pull in passing teachers to use them as visiting experts. They found, however, that many staff found being put on the spot like this stressful in case they were shown up as lacking knowledge in front of the class. This is significantly different to the way the visiting expert approach was carried out at Ayford, where AS was happy to admit that it had taken several minutes' discussion and thought to answer some of the questions posed by AM. There is a real difference in having these discussions in the staffroom compared to having them in front of a class.

\section{c) Informal conversations}

In five of the six of the schools, informal conversations (that is, not part of timetabled meetings) about the curriculum happened between members of the science and mathematics staff. Most participants also noted that this was not common practice in other schools they had worked in.

It was at Eyston where the informal conversations were most significant with science and mathematics staff meeting informally at break times in their joint team room. As EM explained: 'it all started very informally over a cup of coffee, best way!'.

ES and EM clearly felt that it was in the talking and the conversation that they resolved the majority of any difficulties, effectively breaking down the differences in discourse identified by Williams et al. (2016). Both they and the school head suggested that this type of collaboration was easier and more likely in a smaller school (that is, fewer than 5-600 students). 


\section{d) Collaboration in the curriculum and scheme of work}

We are taking curriculum collaboration here to mean other than in project work.

Eyston

At Eyston, EM and ES hadve produced a policy which sets out how language will would be used across the two subjects. Points included that mathematics staff would continue to point out the different types of averages; science staff would make clear that while there were different averages, the one used in science was the mean. They had agreed lists of names for equipment and a common policy as to how graphs were to be laid out. Both EM and ES felt that having this policy allowed them to save time in an overcrowded curriculum. The policy helped to further break down the differences in discourse, knowledge and practice identified by Williams et al. (2016). It did, however, reduce the freedom which individual teachers had in the way that they taught. An example was given of a science teacher who taught students to do graphs in a way that was not in accordance with the policy, although it would be deemed correct in external science examinations, and how he had to be brought into line. It would be much harder to do get consistency of practice with a larger number of teachers, spread further apart in the school.

At Eyston $_{2}$ they had also looked at the skills required of their pupils in each year to ensure that if science requireds mathematical skills that had not yet been taught in mathematics, science teachers were at least aware of it and knew that they would have to teach themese skills. The mathematics department would move their curriculum to aid science if they could,:

The maths department will sometimes say we'll do a bit of extra work on rearranging equations this week because it will support what you're doing [...] we try to show students in science where they could be using [...] the skills they've been learning in maths. [ES] 
bB ut they would not do so at the expense of what they felt is the best order for their curriculum. This is the type of collaboration encouraged by Boohan (2016), although all the Eyston staff acknowledged that it was much easier in a small school.

\section{Effdon}

At Effdon ${ }_{2}$ they were also keen to understand what is taught when by each subject, to allow for better curriculum planning in science, as FS explaineds. FS knew which mathematical skills required in science students were unlikely to have mastered, and planned time in the science curriculum for their coverage.

We realised that we were teaching things in science that they hadn't encountered in maths at all [so] we allowed time when we teach certain science topics to [cover maths skills]. [FS]

\section{Discussion}

Childs et al. (2013) argued that heads of department were important in brokering reform and in promoting collaborative practice. Our initial expectation, therefore, was that heads of department would be the initiators of collaboration. That eөllaboration was not initiated by the heads of science and mathematicsthey were not is perhaps not so surprising given Ball's (1987) observation that relations between heads of department are not always peaceful and can be fraught, with battles for resources and power. If a relationship is already fraught, it would be likely that innovations or changes in teaching practices would be viewed with suspicion and resisted. Our findings demonstrate that in the case of cross-departmental collaboration support from senior leadership is critical.

The question therefore arises as to why the impetus to collaborate came in five cases from those in authority. One interpretation is that teachers have minimal interest in working across departmental boundaries unless they are compelled, or at least 
strongly encouraged, to do so - making AM an unusual exception. It could instead be that the boundaries are so significant, the insulation, in Bernstein's (2000) terms, so strong, that it is extremely challenging for individual teachers to cross them. - The challenges of cross--departmental collaboration could therefore be seen as supporting Hargreaves and Macmillan's (1995)_notion of balkanised departments. The data suggest that a high degree of support from senior leaders is essential in order for collaboration to succeed. From this limited data set it is not possible to answer definitively why the impetus was usually from higher up the school; further work in collaborating schools would be required to do so. In spite of all the barriers, teachers in these six schools had found different ways to circumvent thethose barriers-which undoubtedly existed and they showed that it can be done.

\section{Response to a stimulus}

It is noticeable that in each of these cases there was an external stimulus which catalysed the start of the collaboration. In some cases the stimulus was external to the school, in some cases it was external to the departments, but none of them had begun simply because a science and a mathematics teacher decided to work together. This is not to say that collaboration could not begin spontaneously elsewhere, but that it did not in any of these cases. Wilson et al. (2015) likewise argue that external support is frequently a factor in building and maintaining collaborative practice.

\section{Finding meaningful connections is not straightforward}

Zhang et al. (2015) suggested that it should be relatively easy for teachers to find points of overlap in the content of the two subjects, and they are far from the only authors to make such a suggestion. However, all the teachers interviewed were experienced and none of them hadthey all found making connections across the subjects 
straightforwardchallenging. At Ayford, AM and AS had taken some minutes to recognise angles of incidence and reflection as an example of symmetry. At Ceeton, teachers feared being asked to make connections in front of a class as they were likely to find it challenging. In three of the four schools which had tried interdisciplinary projects (Ayford, Beebury and Ceeton) the teachers had reservations about the science context of the project; reservations were also expressed at Beebury and Ceeton about the mathematics content.

Williams et al. suggest that working across department and disciplinary boundaries requires confronting 'differences in understandings of knowledge, discourse and practice' (2016, p.6), which is far from easy. Indeed, the teachers in this study had found writing meaningful interdisciplinary projects to be extremely challenging. Nelson and Slavit's (2007) study similarly showed teachers struggling to identify common ground, suggesting this challenge is not unique to the curriculum in England.

Afn a related issue is that, teachers in the four schools (Ayford, Beebury, Ceeton and Deecom) with projects also expressed concerns about the rigour or the context of the science and mathematics which could be covered in joint projects. In other words, in prioritising the overlap or joint working there was a loss of subjectspecific content. The longer the project, the more this issue was felt to be problematic. These concerns relate to difficulties identified by Williams et al. (2016), who argue that there is nothing obvious to exchange when science and mathematics teachers work together, or no clear benefit to both sides. In consequence it is difficult to define project outcomes which are meaningful and useful to both subjects. The one apparent exception to these problems in the study was the lesson at Ayford for 15-17s. The content for both science and mathematics was rigorous and meaningful - but it was outside the usual 
school curriculum for both subjects and thus is not an example of common ground within the curriculum.

\section{Conclusions}

This study arose in response to calls for further research into how science and mathematics departments can collaborate (Osborne, 2011). We have explored why science and mathematics teachers begin to collaborate, and-what those collaborations look like in practice and some of the barriers and affordances to collaborative practice.

This study was unusual in not being a follow-up to a specific intervention. It is, however, notable that in all of the schools there was some factor external to the science and mathematics departments which stimulated the start of the collaboration. In none of the schools did thewas collaboration arise spontaneously dueinitiated simply because two to-science and mathematics colleagues deciding decided to work together. This is not to say that collaboration could not arise from within departments in other schools, but when authors-researchers or policy-makers are recommending mathematics/science collaboration, for whatever reason, the necessity of senior leadership support for the success of such an endeavour should be made explicit.

All of the collaborations were regarded as fragile by those involved, with four schools seeing a reduction in joint work compared to the previous academic year and one awaiting a change in school priorities with a new head. When school priorities change such that previous support for collaboration is removed or reduced, it seems to collapse rapidly, again demonstrating the importance of senior leadership support.

Although relatively small in scale, this study has shown that it is possible for mathematics and science teachers to collaborate. This study did not explore, however, whether or how instructional and teaching practices changed as a result of collaboration. There were some hints in the data, for example in Eyston and Effdon where the science 
teachers talked about how knowledge of the mathematics curriculum helped them to know when students were unlikely to have met mathematical content and to plan to teach it themselves if was needed. It would be also interesting to explore whether and how any changes in teaching practices impacted on students' confidence in using mathematics in science, noted by some authors (for example, Dodd \& Bone, 1995) as being low.

Neither collaboration nor finding meaningful connections between the school subjects is as straightforward as is sometimes assumed. This conclusion is evidenced by the difficulties that were reported in finding suitable contexts for collaborating. Finding these points of connection took time and was often frustrating. Suggesting it is relatively easy for teachers to find points of overlap presupposes that teachers are able to see connections between the disciplines, when to do so would require content knowledge of both subjects and an understanding of the connections both within and between them. Having the knowledge and appreciating the connections is recognised as being demanding and evidence of expert practice in just one of the subjects (Turner \& Rowland, 2011); seeing connections across two disciplines when the teacher probably teaches in only one is clearly not as straightforward as many authors seem to assume.

Science and mathematics departments often operate largely independently of one another and, furthermore, departments are often in competition with each other for resources including money, physical space and high achieving students. Such competition can lead to an often uneasy, or even hostile, relationship between heads of departments (Ball, 1987)and there can be uneasy or even hostile relationships between them (Ball, 1987). From the collaborating schools which participated in this study, it would appear that there are two main ways in which such issues can be overcome. The first is through senior leadership team involvement, with leadership teams or 
headteachers encouraging or compelling collaboration. One way of facilitating collaboration is through the creation of science and mathematics faculties, as seen in three of the schools in this study. Such faculties are not guarantees of collaboration, however, in the absence of continued support. Furthermore, it is important to consider what might be lost as a result of creating larger teams. In many English state secondary schools each department can have in excess of 12 teachers, thus the faculty will contain at least 24 teachers. Such a large group could lead to the loss of a feeling of nurture and support that often exists within a department. Bernstein (2000) argues that it is not possible to have both a strong department culture and strong relationships across the school. It is not clear that it would be in the best interest of teachers or students that departmental relationships be broken down in favour of cross-department ones.

The second way to overcome potential hostility is through informal conversation in a pre-existing relationship. To have discussions likely to reveal one as lacking knowledge it is necessary to trust the person with whom one is conversing - and to have the conversation privately rather than in front of a class. As such, forcing these types of conversations is unlikely to be successful and knowing the person a necessary prerequisite to fruitful conversation. Conversations can help science teachers to understand students' difficulties in using mathematics, and help them in planning to take effective account of those difficulties. Taking effective account of what students already know is not a new idea in science education, as demonstrated by the large number of studies about misconceptions, but it is just as important to take account of what students understand and can do mathematically in science.

Collaboration, therefore, is possible but challenging. There are significant barriers which must be overcome in working together, not least that it is a departure from established practice in most schools. This study further emphasises the important 
role that senior leaders' support plays in beginning and maintaining collaboration.

Indeed, any strategy for science-mathematics teacher collaboration should involve senior leadership support to increase its likelihood of success. If the STEM agenda is to be enacted in schools through collaboration there is a very long way to go.

\section{References}

Ball, S. (1987). The Micropolitics of the School. London: Routledge.

BERA. (2011). Ethical guidelines for educational research. London: BERA.

Berlin, D. F., \& White, A. L. (1995). Connecting School Science and Mathematics. In P. House, \& A. Coxford, Connecting Mathematics Across the Curriculum (pp. 22-33). National Council of Teachers of Mathematics.

Berlin, D., \& Lee, H. (2005). Integrating Science and Mathematics Education: Historical Analysis. School Science and Mathematics, 105(1), 15-24.

Bernstein, B. (2000). Pedagogy, symbolic control and identity (2nd ed.). Lanham, Maryland: Rowman \& Littlefield.

Boohan, R. (2016). The language of mathematics in science. Hatfield: ASE.

Braun, V., \& Clarke, C. (2013). Successful Qualitative Research. London: Sage.

Burn, K., Childs, A., \& McNicholl, J. (2007). The potential and challenges for student teachers' learning of subject-specific pedagogical knowledge within secondary school science departments. The Curriculum Journal, 18(4), 429-445.

Carlile, P. (2004). Transferring, Translating, and Transforming: An Integrative Framework for Managing Knowledge Across Boundaries. Organization Science, 15, 555-563.

Charmaz, K. (2006). Constructing grounded theory: A practical guide through qualitative analysis. London: Sage.

Childs, A., Burn, K., \& McNicholl, J. (2013). What influences the learning cultures of subject departments in secondary schools? A study of four subject departments in England. Teacher Development, 17(1), 35-54.

Cohen, L., Manion, L., \& Morrison, K. (2011). Reserach Methods in Education. Abingdon: Routledge.

Czerniak, C. M., Weber, W. B., Sanmann, A., \& Ahern, J. (1999). A literature review of science and mathematics integration. School Science and Mathematics, 99(8), 421-430.

Czerniak, C., \& Johnson, C. (2014). Interdisciplinary science teaching. In N. Lederman, \& S. Abell (Eds.), Handbook of research on science education (Vol. 2, pp. 395-411). New York: Routledge. 
Dodd, H., \& Bone, T. (1995). To what extent does the national curriculum for mathematics serve the needs of science? Teaching Mathematics and its applications, 14(3), 102106.

Edwards, A. (2011). Building common knowledge at the boundaries between professional practices: Relational agency and relational expertise in systems of distributed expertise. International Journal of Educational Research, 50, 33-39.

Frade, C., Winbourne, P., \& Braga, S. M. (2009). A mathematics-science community of practice: reconceptualising transfer in terms of crossing boundaries. For the learning of mathematics, 29, 14-22.

Frykholm, J., \& Glassom, G. (2005). Connecting Science and Mathematics Instruction: Pedagogical context knowledge for teachers. School Science and Mathematics, 127141.

Frykholm, J., \& Glassom, G. (2005). Connecting Science and Mathematics Instruction: Pedagogical context knowledge for teachers. School Science and Mathematics, 105(3), 127-141.

Grossman, P., \& Stodolsky, S. (1995). Content as Context: The Role of School Subjects in Secondary School Teaching. Educational Researcher, 14(5), 5-23.

Hargreaves, A., \& Macmillan, R. (1995). The balkanization of secondary school teaching. In L. Santee Siskin, \& J. Warren Little (Eds.), The Subjects in Question: Departmental Organisation and the High School (pp. 141-171). New York: Teachers College Press.

Honey, M., Pearson, G., \& Schweingruber, H. (2014). STEM Integration in K-12 Education: Status, Prospects, and an Agenda for Research. Washington D.C.: National Academies Press. Retrieved September 2014, from http://www.nap.edu/catalog.php?record_id=18612

Jenkins, E. (2007). School science: A questionable construct? Journal of Curriculum Studies, 39(3), 265-282.

Koirala, H., \& Bowman, J. (2003). Preparing Middle Level Preservice Teachers to Integrate Mathematics and Science: Problems and Possibilities. School Science and Mathematics, 145-154.

Mawhinney, L. (2010). Let's lunch and learn: Professional knowledge sharing in teachers' lounges and other congregational spaces. Teaching and Teacher Education, 26, 972978.

Nelson, T., \& Slavit, D. (2007). Collaborative inquiry among science and mathematics teachers in the USA: professional learning experiences through cross-grade, cross-discipline dialogue. Journal of In-Service Education, 33(1), 23-39.

Orton, T., \& Roper, T. (2000). Science and Mathematics: A relationship in need of counselling? Studies in Science Education, 35(1), 123-153.

Osborne, J. (2011). Science teaching methods: a rationale for practices. School Science Review, 93(343), 93-103. 
Pang, J., \& Good, R. (2000). A Review of the Integration of Science and Mathematics: Implications for Further Research. School Science and Mathematics, 100(2), 73-82.

Perkins, D. (2003). King Arthur's Round Table: How collaborative conversations create smart organizations. New Jersey: John Wiley.

RSA. (2017). Opening Minds. Retrieved June 2017, from RSA Opening Minds: http://www.rsaopeningminds.org.uk/

Rubin, H., \& Rubin, I. (1995). Qualitative Interviewing: The art of hearing data. Thousand Oaks, CA: Sage.

Straw, S., MacLeod, S., \& Hart, R. (2012). Evaluation of the Wellcome Trust Camden STEM Initiative. Slough: NFER. Retrieved from http://www.wellcome.ac.uk/Aboutus/Publications/Reports/Education/WTVM055659.htm

Turner, F., \& Rowland, T. (2011). The knowledge quartet as an organising framework for developing and deepening teachers' mathematics knowledge. In K. Ruthven, \& T. Rowland, Mathematical knowledge in teaching (pp. 195-212). London and New York: Springer.

Venville, G., Wallace, J., Rennie, L., \& Malone, J. (2002). Curriculum Integration: Eroding the high ground of science as a school subject. Studies in Science Education, 37(1), 43-83.

Walford, G. (2005). Research ethical guidelines and anonymity. International Journal of Research \& Method in Education, 28(1), 83-93.

Weinberg, A., \& Meeking, L. (2017). Toward Meaningful Interdisciplinary Education: High School Teachers' Views of Mathematics and Science Integration. School Science and Mathematics, 117(5), 204-213.

Wengraf, T. (2001). Qualitative Research Interviewing. London: Sage.

Williams, J., Roth, W.-M., Swanson, D., Doig, B., Groves, S., Omuvwie, M., . . Mousoulides, N. (2016). Interdisciplinary Mathematics Education. Springer Open. Retrieved September 2016, from http://download.springer.com/static/pdf/540/bok\%253A978-3-319-422671.pdf?originUrl=http\%3A\%2F\%2Flink.springer.com\%2Fbook\%2F10.1007\%2F978-3319-42267-

1\&token2=exp=1473326793 acl=\%2Fstatic\%2Fpdf\%2F540\%2Fbok\%25253A978-3-31942267-1.pdf\%3ForiginUrl\%3Dhttp\%25

Wilson, S., Schweingruber, H., \& Nielsen, N. (2015). Science Teachers' Learning: Enhancing Opportunities, Creating Supportive Contexts. Washington DC: National Academies Press.

Wong, V. (2018). The relationship between school science and mathematics education. PhD Thesis, King's College London, London.

Wong, V., \& Dillon, J. (2019). 'Voodoo maths', asymmetric dependency and maths blame: why collaboration between school science and mathematics teachers is so rare. International Journal of Science Education, 41(6), 782-802. 
Zhang, D., Orrill, C., \& Campbell, T. (2015). Using the mixture Rasch model to explore knowledge resources students invoke in mathematic and science assessments. School Science and Mathematics, 115, 356-365. 